\title{
Adult-onset distal myopathy due to VCP mutation
}

INSERM

\section{Source}

INSERM. (1999). Orphanet: an online rare disease and orphan drug data base. Adultonset distal myopathy due to VCP mutation. ORPHA:329478

Adult-onset distal myopathy due to VCP mutation is a rare, genetic distal myopathy disorder characterized by middle age-onset of distal leg muscle weakness, atrophy in the anterior compartment resulting in foot drop, without proximal or scapular skeletal muscle weakness. Rapidly progressive dementia, Paget disease of bone and hand weakness have been reported. Muscle biopsy shows pronounced myopathic changes with rimmed vacuoles. 